\title{
A marine voyage of discovery
}

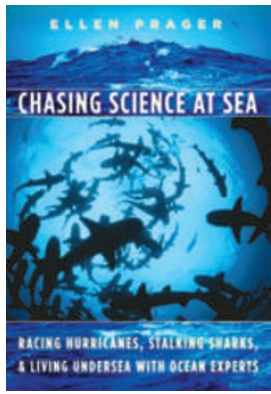

Chasing Science at Sea

By Ellen Prager

UNIV. CHICAGO PRESS: 2008. 178PP. $\$ 22.50$

\footnotetext{
$\square$
} ata collection in ocean science research is characterized by ever-changing conditions and unanticipated events. Ellen Prager documents the field experiences of scientists that illustrate this unpredictability: her highly readable stories show the human side of scientists as well as the challenges of conducting research on the high sea, in the deep ocean, or near to shore.

Too many students who begin their research believe that there is a single path towards achieving scientific results and an answer to a question. This book provides a fresh look at the nature of science, illustrating avenues towards scientific discovery beyond the traditional 'scientific method' that we are all taught in the classroom - develop a hypothesis and design a methodology to test it. Prager shows how serendipitous, unexpected occurrences broaden and perhaps enlighten our scientific understanding. An apt example is the incredible discovery in the 1970 s by a group of geologists who, when studying submarine hydrothermal vents in the Galapagos rift, came across a thriving, previously unknown, deep-sea community of organisms co-existing in extreme environments of intense heat and pressure several kilometres beneath the sunlit surface. As nobody had expected abundant life in this extreme environment, there was no biologist included on the expedition. Her account of such historic moments in ocean science will certainly tempt any reader to study the sea floor, its life and its mysteries.

Prager discusses a variety of ways in which science is accomplished. Drawing from experiences of her colleagues, she shows how bias, pre-conceived notions and a refusal to accept new ideas have at times impeded progress. For example, a colleague's proposal of underwater cementation as a cause for limestone formation initially met with the resistance of many geologists, who were eventually compelled to alter their opinions in the face of accumulating evidence. As Prager writes, "Today submarine cementation is taken for granted and explained in textbooks".

Stating that "it is just as important to learn how nature doesn't work as it is to learn how it does", Prager highlights one of the critical lessons many scientists come across in their careers: that some goals can only be reached by painstakingly ruling out the dead ends and changing misconceptions through acquiring additional data and information. She accurately points out that ruling out hypotheses can be as important as ruling them in.

Readers learn about the day-to-day life and the unusual occurrences at sea encountered by ocean scientists. Life in undersea research habitats - such as Hydrolab and Aquarius - can often be cramped and uncomfortable. These conditions are exemplified by tales of exploding portable toilet tanks, 100\% humidity and food that is difficult to taste, as well as the curiously interesting 'martini effect' caused by nitrogen narcosis. These experiences are a reality that scientists must sometimes deal with. However, Prager clearly illustrates how hardships and potential dangers are most often offset by the thrill of the ride and the excitement of being at sea, conducting science.

Prager clearly believes that field observations are an essential part of the ocean sciences, and that oceanographers should be immersed in the marine realm from time to time, either on research vessels, in undersea habitats such as Aquarius, or making observations from submersibles or with a scuba tank. An enjoyable chapter is devoted to many "Tales of Wonder" that illustrate again and again the thrill of first-hand exploration and discovery, including night time observations of coral-spawning events, astounding displays of bioluminescent 'fireworks' in the deep sea, an army of sea urchins mowing down sea grass during their seafloor traverse, and wondrous aggregations of 1,500 whale sharks off the coast of Mexico. It soon becomes clear why so many ocean scientists, including many who are prone to seasickness, would not trade their fieldwork for a full-time spot behind a computer.

By emphasizing the human elements of excitement, curiosity, ingenuity, tolerance to adverse conditions and an unequivocal passion for discovery, this book is likely to dissolve any perceived association of ocean scientists with lab coats and calculators.
Perseverance, dedication and courage are also qualities of a successful scientist she highlights throughout the book. Prager's flair for story-telling, even when the stories aren't her own but those of colleagues, makes the book an enjoyable read. Her tales have certainly made me appreciate even more my own career in ocean science research and education.

At the same time, the pitfalls of funding and support for fieldwork, research and graduate studies are discussed. Prager describes funding as a seemingly "lifelong pursuit in science". Her own account is not uncommon, where, despite having a fellowship for her time as a graduate student, she still had to seek additional resources to pay the bills. Her point of comparing the annual space exploration funding (at $\$ 17$ billion) with annual ocean science funding (at only $\$ 700$ million) is an eye opener. We have explored less than $5 \%$ of the sea so far; yet, the oceans cover $71 \%$ of the planet!

One criticism: the book has a rough start. The introductory chapter jumps around - akin to Prager's tale of a flying fish on a ship's deck - and is therefore rather hard to follow. She touches on funding, red tides, discomforts at sea, jobs, upwelling and more, in a mere 10 pages of this chapter. Her description of the struggle to find funding would be better placed later in the book, when the reader has been absolutely convinced of the value of supporting expensive fieldwork and exploration at sea. However, once the introduction has been negotiated, the stories will carry the reader from chapter to chapter. A brief summary at the end of each chapter is particularly useful in highlighting the relevance of the stories documented.

My favourite line of the book is "...in the ocean we don't know what we don't know". For me, this is truly the heart of doing science: seeking not only to answer questions, but to discover the questions that we did not know existed or could never have imagined. Along with Prager, I too would like to encourage all who can to take part in the exciting science of the ocean.

\section{REVIEWED BY LESLIE R. SAUTTER \\ Leslie R. Sautter is the Director of Project Oceanica (http://oceanica.cofc.edu) and Associate Professor in the Department of Geology and Environmental Geosciences, College of Charleston, 66 George St, Charleston, South Carolina 29424-0001, USA. e-mail:SautterL@cofc.edu}

